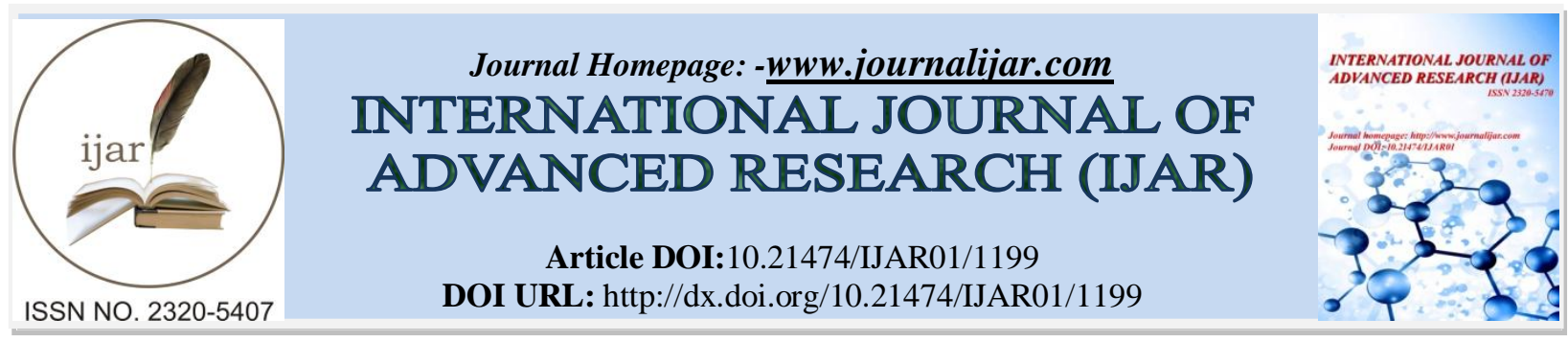

RESEARCH ARTICLE

\title{
PV FED INTERLEAVED BOOST CONVERTER FOR THE SPEED CONTROL OF SEPARATELY EXCITED DC MOTOR USING FLC.
}

\author{
Karthika M. \\ Asst.professorNew Horizon College of Engineering, Bangalore.
}

\section{Manuscript Info}

Manuscript History

Received: 13 June 2016

Final Accepted: 12 July 2016

Published: August 2016

Key words:-

Boost converter, interleaved, photovoltaic (PV) power-generation

systems, resonant converter, soft-

switching, fuzzy logic, dc motor.

\section{Abstract}

In this paper, the efficiency for the DC/DC converter of the PV power conditioning system is raised by an interleaved soft-switching boost converter (ISSBC). The switching losses are minimized by adopting a resonant soft-switching method and the current rating of the switching device is decreased. The gate pulses for the dc/dc converter is generated using PI controller. The speed of the dc separately excited motor which is driven by the output of ISSBC is controlled using FUZZY logic controller.

\section{Introduction:-}

Solar energy as one of many favored renewable energy resources has become an important part of power generation in the new millennium. Solar energy is environmental friendly and which generates electricity without any dangerous emissions. Furthermore, the sunlight is free and it is available for long hours in a day throughout the year. The output power of the solar cell is easily changed by the surrounding conditions such as irradiation and temperature, and also its efficiency is low.

But high efficiency is required for the power conditioning system (PCS), which transmits power from the PV array to the load. This paper proposes a high efficiency dc/dc boost converter to increase the efficiency. The proposed single-switch type soft-switching boost converter can minimize switching loss by adopting a resonant soft-switching method. And, no additional switches are needed for soft switching. Also the boosted output of an Interleaved Soft Switching Boost Converter (ISSBC) is used to control the speed of separately excited DC motor using FUZZY logic.

In this paper, the feasibility of Fuzzy Logic as an effective control tool for DC motors is dealt. ThisFuzzy Logic Controller (FLC) is showing a better performance than conventional controllers.

\section{Proposed Topology:-}

The present single-switch type soft-switching boost converter which is used in PV power conditioning system can minimize the switching loss by adopting a resonant soft-switching method. However the drawback of this converter is that the voltage across the switch is very high during the resonance mode. The voltage across

The switch depends on the parameters of the resonant components and the resonant inductor current.

Corresponding Author:-Karthika M.

Address:-Asst.professorNew Horizon College of Engineering, Bangalore. 


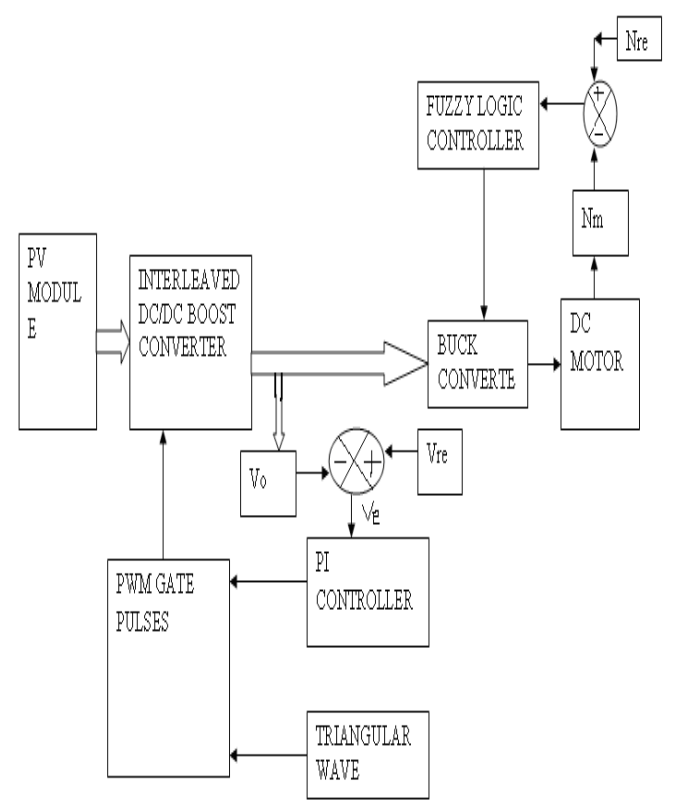

Fig. 1:- Block diagram representation of proposed topology

Since the interleaved method distributes the input current according to each phase, it can decrease the current rating of the switching device. Also, it can reduce the input current ripple, output voltage ripple, and size of the passive components. The soft-switching interleaved boost converter can not only exploit the interleaved converter but also reduce switching losses through the soft-switching technique. Therefore, the output power of the PV array can be boosted with high efficiency.

In the proposed system the dc output of inter leaved soft switching boost converter is fed to the PI controller and to the dc separately excited motor to control its speed. The proportional term does the job of fast-acting correction which will produce a change in the output as quickly as the error arises. The integral action takes a finite time to act but has the capability to make the steady-state speed error zero. The output of PI controller is compared with reference signal to produce the gate pulses for the IGBT switches.

The boosted output of the ISSBC is used to control the speed of separately excited DC motor using FUZZY logic. After tuning the FLC, its performance for set-point tracking is studied. The closed response of the motor with a Fuzzy Logic Controller is given. It can be seen from the response that, the motor reaches the set point without oscillations and overshoot.

This Fuzzy Logic Controller (FLC) is showing a better performance than conventional controllers. The simulink model of the proposed scheme employing fuzzy controller has been built using MATLAB.

Proposed Soft Switching BoostConverter:-

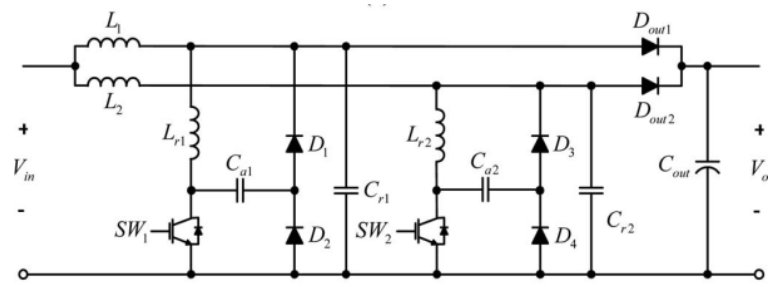

Fig.2:- Inter-leaved soft switching boost converter.

Fig2. Shows an interleaved soft-switching boost converter (ISSBC) proposed in this paper.

Two single-phase soft-switching boost converters are connected in parallel and then to a single output capacitor. The two PWM signal difference is $180^{\circ}$ when each switch is controlled with the interleaving method. 
Table I:-parameters.

\begin{tabular}{c|c|c|c}
\hline \hline Parameter & Symbol & Value & Unit \\
\hline \hline Input voltage & $V_{i n}$ & $200-350$ & $V$ \\
\hline Output voltage & $V_{o}$ & 400 & $V$ \\
\hline Rated power & $P_{o}$ & 1.2 & $\mathrm{~kW}$ \\
\hline Main inductor & $L_{1}, L_{2}$ & 1 & $\mathrm{mH}$ \\
\hline Resonant inductor & $L_{r l}, L_{r 2}$ & 50.6 & $\mu \mathrm{H}$ \\
\hline Resonant capacitor & $C_{r l}, C_{r 2}$ & 100 & $n F$ \\
\hline Auxiliary capacitor & $C_{a l}, C_{a 2}$ & 10 & $n F$ \\
\hline Output capacitor & $C_{o u t}$ & 10 & $\mu F$ \\
\hline Switching frequency & $f_{s w}$ & 30 & $\mathrm{kHz}$ \\
\hline \hline
\end{tabular}

\section{De Motor:-}

Developments of high performance motor drives are very essential for industrial applications. A high performance motor drive system must have good dynamic speed command tracking and load regulating response. DC motors provide excellent control of speed for acceleration and deceleration. The power supply of a DC motor connects directly to the field of the motor which allows for precise voltage control, and is necessary for speed and torque control applications.

There are several methods for controlling the DC motor. Basically, the speed of DC motor can be done by controlling the amount of current flow or voltage supplied into it. The new method to control the speed of DC motor is fuzzy logic controller.

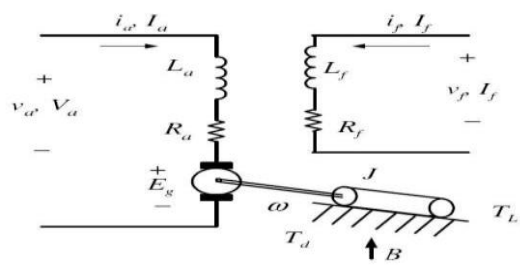

Fig.3:- Model of Separately Excited DC Motor.

As shown in Fig3 the field windings are used to excite the field flux. Armature current is supplied to the rotor via brush and commutator for the mechanical work. Interaction of field flux and armature current in the rotor produces torque.

\section{Operation:-}

When a separately excited motor is excited by a field current of $i_{\mathrm{f}}$ and an armature current of $i_{a}$ flows in the circuit, the motor develops a back emf and a torque to balance the load torque at a particular speed.

The $i_{\mathrm{f}}$ is independent of the $\mathrm{i}_{\mathrm{a}}$. Each winding are supplied separately. Any change in the armature current has no effect on the field current. The $i_{\mathrm{f}}$ is normally much less than the $\mathrm{i}_{\mathrm{a}}$.

\section{Speed Control:-}

The basic principle behind DC motor speed control is that the output speed of DC motor can be varied by controlling armature voltage for speed below and up to rated speed keeping field voltage constant. The output speed is compared with the reference speed and error signal is fed to speed controller. Controller output will vary whenever there is a difference in the reference speed and the speed feedback. The output of the speed controller is the control voltage that controls the operation duty cycle of converter. The converter output give the required $\mathrm{V}_{\mathrm{a}}$ required to bring motor back to the desired speed.

\section{Fuzzy Logic Controller (FLC):-}

FLC uses different strategies for motor speed control.FLC process is based on experiences and Linguistic definitions instead of system model. It is not required to know exact system model to design FLC.

The goal of designed FLC in this study is to minimize speed error (e). The bigger speed error the bigger controller input is expected. In addition, the change of error (ce) plays an important role to define controller input. The output variable is the change in control variable (du) of motor. The general considerations in the design of the controller are: 
1. If both e and ceare zero, then maintain the present control setting i.e. $d u=0$

2. If e is not zero but is approaching this value at a satisfactory rate, then maintain the present control setting.

3. If e is growing then change the control signal du depending on the magnitude and sign of e and ceto force e towards zero.

\section{Simulation Results:-}

The Power sim simulation software was used to analyze the operational characteristics of the proposed softswitching interleaved boost converter. The design parameters for the simulation are shown in Table I.

Fig.4 shows the voltage waveforms of the resonant capacitor and auxiliary resonant capacitor. The peak voltage of $\mathrm{V}_{\mathrm{Ca}}$ is higher than that of the resonant capacitor voltage $\mathrm{V}_{\mathrm{Cr}}$.

Fig.6 shows the current waveforms of the main inductor and resonant inductor of the proposed soft-switching interleaved boost converter. The main inductor currents increase and decrease linearly according to the gate signals.

When the switch turns off, the auxiliary resonant capacitor voltage $\mathrm{V}_{\mathrm{Ca}}$ increases and then decreases to the zero level, satisfying the ZVS condition.

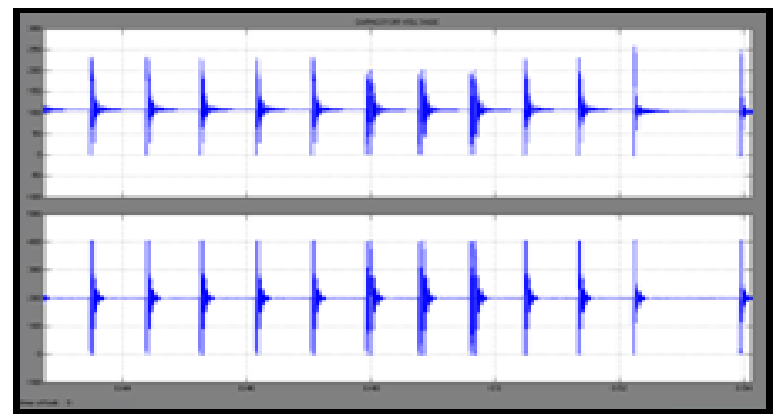

Fig.4:- Simulation results of voltage across capacitor.

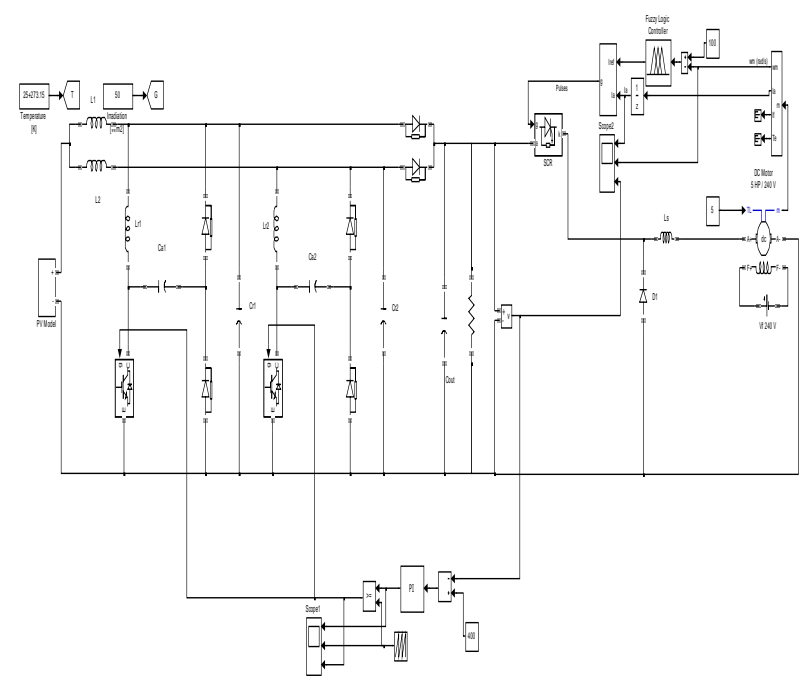

Fig.5:- SimuLink Diagram Of Proposed Converter for the speed control of dc motor. 


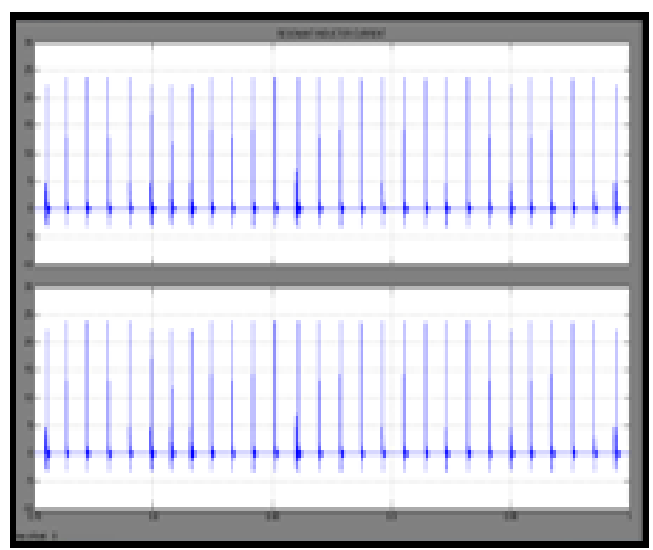

Fig.6:- Simulation results of current through inductor.

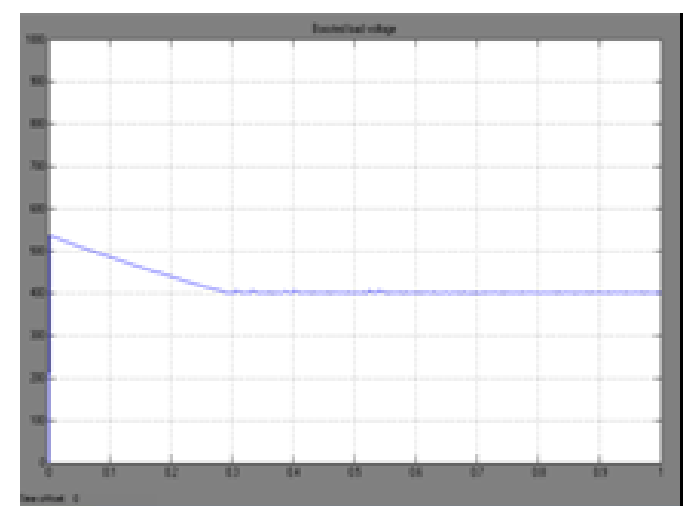

Fig.7:- Dc boosted output of ISSBC.

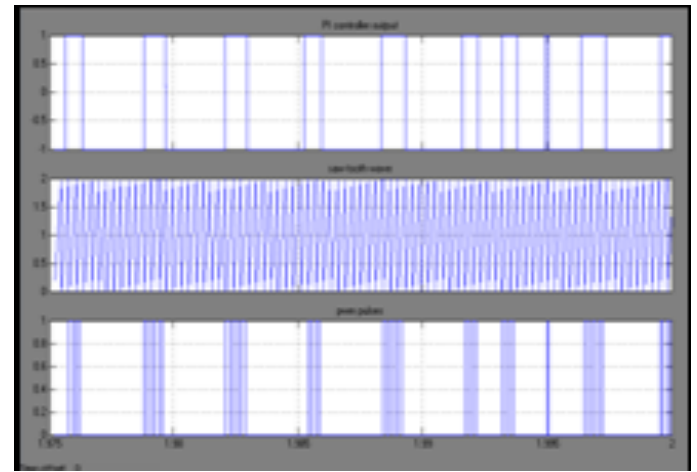

Fig.8:- Simulation result of PWM pulses.

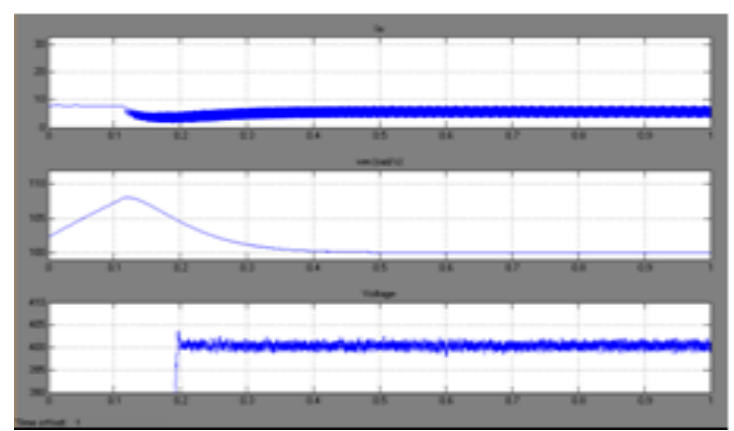

Fig.9:- Simulation result of speed,current and voltage output waveforms. 


\section{Conclusion:-}

In this paper, we proposed a soft-switching interleaved boost converter using resonance. A PV simulator and current control was performed using PI controller.

The interleaved boost converter simulation results have achieved their advantages. The simulation of the PV array and interleaved boost converter has been evaluated using Matlab/simulink and speed control of DC motor has been done by Fuzzy tool box.

The FLC performance has good set-point tracking. Moreover, because of their reliance on rules based on expert knowledge, they provide their environment, a higher machine intelligent quotient. The results tend to move smoothly across the control surface. FLC can therefore be an effective control strategy for the speed control of d.c. motor.

\section{References:-}

1. D. Min, J.-P. Lee, and J.-H. Kim(2008), "A novel grid- connected PV PCS with new highefficiency converter," J. Power Electron., vol. 8, no. 4,pp. 309-316, Oct.

2. Doo-Yong Jung, Young-HyokJi, Sang-Hoon Park, Yong-Chae Jung, and Chung-Yuen Won (2011), "Interleaved Soft-Switching Boost Converter for Photovoltaic Power-GenerationSystem"- Senior Member, IEEE

3. H. Bodur and A. F. Bakan (2004), "A new ZVT-ZCT-PWM DC-DC converter," IEEE Trans. Power Electron., vol. 19, no. 3, pp. 676-684, May.

4. NurzlizaAli(2008)“Fuzzy logic controller for controlling DC motor speed using MATLAB applications" Facultyof Electrical\&ElectronicEngineering,University Malaysia Pahang,NOVEMBER,

5. SaffetAyasun, GuLtekinKarbeyaz (2006)“ DC Motor Speed Control Methods Using MATLAB/ Simulink and Their Integration into Undergraduate Electric MachineryCourses"Department of Electrical and Electronics Engineering, Nigde University, Nigde 51100, Turkey 23 July

6. "Power loss analysis of two-stage PV-PCS using interleaved soft switchingdc-dc converter "Jae-Hyung Kim; Chung-Yuen Won; Su-Won Lee; Byung-Kuk Lee; Chong-Sun KimPower Electronics and Motion Control conference, 2009. IPEMC '09. IEEE 6th InternationalConference Publications

7. "Interleaved soft switching boost converter with MPPT for photovoltaic power generation system "D. Amudhavalli.; M. Meyyappan.; S. Imaya.; Kumari. V PreethaInformation Communication and Embedded Systems (ICICES), 2013 International Conference onIEEE Conference Publications 